\title{
The crystal structures of the low-temperature and high-pressure polymorphs of nitric acid $\dagger$
}

\author{
D. R. Allan, ${ }^{a}$ W. G. Marshall, ${ }^{b}$ D. J. Francis, ${ }^{b}$ I. D. H. Oswald, $\$^{c}$ C. R. Pulham ${ }^{c}$ and C. Spanswick ${ }^{c}$ \\ Received 13th November 2009, Accepted 10th February 2010 \\ First published as an Advance Article on the web 11th March 2010 \\ DOI: $10.1039 / \mathrm{b} 923975 \mathrm{~h}$
}

A new high-pressure phase of pure nitric acid $\left(\mathrm{HNO}_{3}\right)$ has been characterised at $1.6 \mathrm{GPa}$ at room temperature by high-pressure neutron powder and X-ray single-crystal diffraction techniques. This is the first crystalline phase obtained upon compression of liquid nitric acid at room temperature and appears to be the stable phase up to pressures of at least $4 \mathrm{GPa}$. The crystal structure of this new phase shows some similarities to that of the low-temperature phase of nitric acid at ambient pressure, which has been redetermined as part of this study. Both structures share a herringbone packing of hydrogen-bonded molecular catemers, although the presence of disorder within the hydrogen bonds within one of the catemers of the low-temperature phase makes its structure comparatively more complex.

\section{Introduction}

Nitric acid $\left(\mathrm{HNO}_{3}\right)$ is a well-known strong, corrosive inorganic acid. Along with the other mineral acids, such as sulfuric acid $\left(\mathrm{H}_{2} \mathrm{SO}_{4}\right)$ and phosphoric acid $\left(\mathrm{H}_{3} \mathrm{PO}_{4}\right)$, it is a ubiquitous and commercially important chemical that finds widespread applications as a laboratory reagent and as a bulk industrial compound. Particular applications of nitric acid include, the synthesis of explosives, such as nitroglycerin and trinitroluene, and the manufacture of agricultural fertilizers such as ammonium nitrate. Unlike sulfuric and phosphoric acid, which both have a tetrahedral $\mathrm{sp}^{3}$ arrangement of oxygens around the central atom, the molecule of nitric acid has a planar $\mathrm{sp}^{2}$ arrangement of three oxygen atoms around the central nitrogen. It can be anticipated, therefore, that the hydrogen bonding geometries of the crystalline phases of nitric acid, and its hydrates, will differ markedly from those of sulfuric acid and phosphoric acid.

As nitric acid can be formed in the atmosphere by the conversion of nitrogen monoxide into nitrogen dioxide, and ultimately into nitric acid, much recent research on nitric acid, its hydrates and related compounds has generally been associated with its environmental effects and the physiocochemistry of nitrogen oxides in the Earth's atmosphere. ${ }^{1,2}$ Atmospheric nitric acid is one of the main constituents of polar stratospheric clouds and is thought to be one of the main contributors to the chemistry of ozone depletion. ${ }^{3}$ As the nitrogen monoxide required for the production of atmospheric nitric acid is closely associated with the combustion of fossil fuels,

${ }^{a}$ Diamond Light Source, Harwell Science and Innovation Campus, Chilton, Oxfordshire,Didcot,UK OX110CE.E-mail: david.allan@diamond.ac.uk; Fax: +44 (0) 1235 778499; Tel: +44 (0) 1235778644

${ }^{b}$ ISIS Neutron Facility, STFC Rutherford Appleton Laboratory, Harwell Science and Innovation Campus, Chilton, Didcot, Oxon, UK OX11 0QX

'School of Chemistry and Centre for Science at Extreme Conditions, University of Edinburgh, Kings Buildings, West Mains Road, Edinburgh, UK EH9 3JZ

$\dagger$ CCDC reference numbers 754934 and 754935 . For crystallographic data in CIF or other electronic format see DOI: 10.1039/b923975h

\$Now at Strathclyde Institute of Pharmacy and Biomedical Sciences, University of Strathclyde, The Sir John Arbuthnott Building, 27 Taylor Street, GLASGOW, UK G4 0NR there has been an accompanying interest in the human influence on the chemistry of ozone depletion through studies of the chemical composition and formation processes of these clouds. The detailed understanding of the phase behaviour of nitric acid, nitric acid hydrates and the crystalline structures of their various solid phases is a crucial component of this work.

There have been a number of structural studies of the crystalline phases of nitric acid and its hydrates ${ }^{4,5}$ including the more recent studies of two phases of nitric acid dihydrate ${ }^{6,7}$ at ambient pressure. The work presented here forms part of an ongoing programme to study the high-pressure structural behaviour of small-molecule inorganic systems, as a result of which we have identified new hydrate phases of nitric acid ${ }^{8,9}$ as well as new phases of sulfuric acid, ${ }^{10}$ sulfuric acid monohydrate, ${ }^{11}$ and phosphoric acid. ${ }^{12}$

The low-temperature ambient-pressure crystal structure of nitric acid, which was first determined by Luzzati, ${ }^{13}$ crystallises in space group $P 2_{1} / c$ below its melting point of $232 \mathrm{~K}$. Despite the relative simplicity of the nitric acid molecule, the crystal structure is surprisingly complex with four molecules in the asymmetric unit. The molecules form hydrogen-bonded chains (catemers) directed along the crystallographic $b$-axis and these are packed in a herringbone arrangement. In his original structure determination, Luzzati noted the likely presence of disorder in the structure, as indicated by continuous streaks of diffracted intensity, parallel to $0 \mathrm{kl}$, on the Weissenberg photographs, and there was an ambiguity between the assignment of space group $P 2_{1} / a\left(P 2_{1} / c\right.$ in the conventional setting) and the recorded absence conditions. Given that the hydrogen atom locations were also not found, it is now timely to redetermine the crystal structure of the lowtemperature phase using modern single-crystal X-ray diffraction techniques.

More recently, nitric acid has been studied using high-pressure Raman spectroscopy techniques to establish the structural and chemical transformations induced by pressures up to $50 \mathrm{GPa} .{ }^{14}$ Crystallisation was observed to occur at $1.4 \mathrm{GPa}$ and on further compression a marked change, from $-1 \mathrm{~cm}^{-1} \mathrm{GPa}^{-1}$ to $-4.5 \mathrm{~cm}^{-1} \mathrm{GPa}^{-1}$, was observed at $10 \mathrm{GPa}$ in the pressure derivative $(d v / d p)$ of the nitro group elongation mode $v s\left(\mathrm{NO}_{2}\right)$. By contrast, the $v(N-\mathrm{OH})$ mode showed a steady increase in 
frequency with pressure, with a $d v / d p$ of $4.5 \mathrm{~cm}^{-1} \mathrm{GPa}^{-1}$, over the 0-30 GPa interval, indicating a progressive strengthening of the hydrogen bonds between neighbouring molecules. Ionisation of the molecules above $30 \mathrm{GPa}$, with the formation of the $\mathrm{NO}_{3}{ }^{-} \mathrm{H}^{+}$ salt, was suggested due to the apparent absence of all other bands apart from the $v s\left(\mathrm{NO}_{3}{ }^{-}\right)$of the nitrate ion. The sharp discontinuity in $d v / d p$ of the $v s\left(\mathrm{NO}_{2}\right)$ symmetric elongation mode at $10 \mathrm{GPa}$ could not be fully rationalised from the experimental data and, more recently, Méreau and Mathieu ${ }^{15}$ have conducted a theoretical investigation of the high-pressure systematics of nitric acid to establish a structural mechanism for this behaviour. They proposed that there is a two-step ionisation of the $\mathrm{HNO}_{3}$ molecules, with $75 \%$ of this process completed by $10 \mathrm{GPa}$ and total ionisation occurring at $30 \mathrm{GPa}$ via a structural phase transition induced by proton-tunnelling. In the absence of a high-pressure structure determination of nitric acid, their calculations assumed that the crystal structure obtained on initial compression into the solid phase from the liquid at $1.4 \mathrm{GPa}$ and room temperature is the same as that obtained on freezing below $232 \mathrm{~K}$ at ambient pressure, which was termed the $\alpha$ phase. The calculations also assumed that the transition to the $\beta$ phase, at $30 \mathrm{GPa}$, involves only a migration of the hydrogen atoms, which link the $\mathrm{HNO}_{3}$ molecules in a dimeric arrangement in the $\alpha$ phase and shift to form the ribbon-like chains of the $\beta$ phase, with minimal effect on the heavy atom positions and with no change in the crystal symmetry.

Here we report the crystal structure of the high-pressure phase of nitric acid (here termed phase-II to distinguish it from the theoretically proposed $\beta$ phase of Méreau and Mathieu ${ }^{15}$ ), which is the first crystalline phase obtained by compression of the liquid to pressures just in excess of $1.0 \mathrm{GPa}$, along with a redetermination of the low-temperature, ambient-pressure, phase-I structure (here we relabel the $\alpha$ phase as phase-I for consistency). Both structures are found to adopt the monoclinic $P 2_{1} / c$ symmetry and are characterized by a herring-bone packing of catemeric hydrogen bonded molecular chains which run parallel to the crystallographic $b$-axis. The high-pressure phase-II crystal structure has two molecules in the asymmetric unit making it somewhat simpler than that of phase-I and although the two structures are superficially alike there are some significant differences between them.

\section{Experimental}

\section{Preparation of nitric acid and $d_{1}$ nitric acid}

Nitric acid was prepared by adding sulfuric acid $(98 \mathrm{wt} \%, 10.0 \mathrm{~g}$, $\left.5.4 \mathrm{~cm}^{3}, 0.10 \mathrm{~mol}\right)$ to potassium nitrate $(10.5 \mathrm{~g}, 0.10 \mathrm{~mol})$ and distilling off the product at $83-84{ }^{\circ} \mathrm{C}$. The resulting nitric acid was briefly degassed under vacuum to remove excess dissolved nitrogen oxides. The $d_{1}$-nitric acid was prepared by the same method using $d_{2}$-sulfuric acid.

\section{Redetermination of the ambient-pressure phase-I crystal structure of nitric acid}

A sample was drawn into a capillary (o.d. $0.48 \mathrm{~mm}$ ) and flamesealed. A polycrystalline mass was produced by freezing the liquid at $210 \mathrm{~K}$. A single crystal was grown using the laser zone refinement technique of Boese and Nussbaumer. ${ }^{16}$ Before the crystal was grown the sample was zone-refined to purify the sample in the capillary should any degradation products have been formed during the sealing process. Datasets were collected at $210 \mathrm{~K}$ and also at $150 \mathrm{~K}$ (standard data collection temperature); no phase transitions were observed on cooling to this temperature.

$\mathrm{X}$-ray diffraction intensities were collected with Mo-K $\alpha$ radiation $(\lambda=0.71073 \AA)$ on a Bruker SMART Apex CCD diffractometer ${ }^{17}$ equipped with an Oxford Cryosystems Cryostream-Plus variable-temperature device. ${ }^{18}$ Absorption corrections were carried out using the multiscan procedure $S A D$ $A B S .{ }^{19,20}$ The structure of nitric acid at $210 \mathrm{~K}$ was solved by direct methods ${ }^{21}$ and refined by full-matrix least-squares against $F^{2}$ using all data. ${ }^{22}$ Hydrogen atoms were located in difference maps and all $\mathrm{OH}$ distances were refined with a distance restraint of $0.82(5) \AA$. All non-H atoms were modeled with anisotropic displacement parameters.

The diffraction intensities collected showed unusual systematic absences that did not fit those expected for an orthorhombic or monoclinic lattice. The data showed absences signifying $2_{1}$-screw axes along all three directions as well as absences for a $c$-glide perpendicular to the $b$-direction; no accompanying mirrors were observed for the other two directions. Solving the data by direct methods in monoclinic $P 2_{1} / c$ gave a reasonable solution, although the R-factor remained rather high (see below). The anomaly in the systematic absences observed for this dataset can be explain by the position of the molecules within the unit cell. The fractional coordinates of the central nitrogen atom for each independent molecule have an $x, y$ or $z$ value close to $0, \frac{1}{4}, \frac{1}{2}, \frac{3}{4}$, which creates artificial systematic absences that are not related to the presence of a true symmetry operation. These observations were also made by Luzzati ${ }^{13}$ in his earlier study.

To further compound the problem of anomalous systematic absences, the low temperature form of nitric acid crystallises with a $\beta$-angle close to $90^{\circ}$ and is therefore susceptible to twinning. The refinement of the original model that was output by $S I R-92$ gave a final $R$-factor of $23.15 \%$. By adding a twin component for a two-fold rotation around the $a$-direction this value dropped to $3.54 \%$ with a refined twin scale factor of $52 \%$.

\section{Determination of the high-pressure phase-II crystal structure of nitric acid}

The sample was prepared by loading nitric acid into a MerrillBassett diamond-anvil cell ${ }^{23}$ equipped with $600 \mu \mathrm{m}$ culet diamonds and a tungsten gasket. The sample was pressurised at room temperature until several crystallites were observed. The temperature was then increased, using a hand-held hot air blower, so that the polycrystalline sample was partially remelted, and subsequently cycled close to this elevated melting temperature in order to reduce the number of crystallites. A single-crystal was eventually obtained at a pressure of $1.6 \mathrm{GPa}$, as determined using the ruby fluorescence technique. $^{24}$

$\mathrm{X}$-ray diffraction data $(\mathrm{Mo}-\mathrm{K} \alpha)$ were collected on a Bruker kappa CCD diffractometer using a strategy that is a slight modification of that described by Dawson et al. ${ }^{25}$ where four new additional runs were included with $\chi$-settings of $+90^{\circ}$ and $-90^{\circ}$. The data were integrated using the program $S A I N T^{26}$ using 'dynamic masks' to avoid integration of regions of the detector shaded by the body of the pressure cell. ${ }^{25}$ Absorption corrections were carried out with the programs $S A D A B S^{19}$ and $S H A D E{ }^{27}$ 
Table 1 Crystallographic data for single crystal X-ray diffraction

\begin{tabular}{|c|c|c|c|}
\hline $\mathrm{T} / \mathrm{P}$ & $210 \mathrm{~K}$ & $150 \mathrm{~K}$ & $293 \mathrm{~K} / 1.6 \mathrm{GPa}$ \\
\hline Formula & $\mathrm{HNO}_{3}$ & $\mathrm{HNO}_{3}$ & $\mathrm{HNO}_{3}$ \\
\hline Weight & 63.01 & 63.01 & 63.01 \\
\hline Radiation & Mo Ka & Mo Ka & Mo Ka \\
\hline Crystal system & Monoclinic & Monoclinic & Monoclinic \\
\hline Space group & $P 2_{1} / c$ & $P 2_{1} / c$ & $P 2_{1} / n$ \\
\hline$a / \AA$ & $6.3689(3)$ & $6.3031(2)$ & $7.3163(4)$ \\
\hline$b / \AA$ & $8.6046(4)$ & $8.5847(2)$ & $8.4176(11)$ \\
\hline$c / \AA$ & $16.4141(9)$ & $16.3122(4)$ & $7.3135(11)$ \\
\hline$\alpha /^{\circ}$ & 90 & 90 & 90 \\
\hline$\beta /^{\circ}$ & $90.055(4)$ & $90.039(2)$ & $116.895(6)$ \\
\hline$\gamma /{ }^{\circ}$ & 90 & 90 & 90 \\
\hline Volume $/ \AA^{3}$ & $899.52(8)$ & $882.66(4)$ & $401.69(9)$ \\
\hline $\mathrm{Z}$ & 16 & 16 & 8 \\
\hline $\mathrm{D} c\left(\mathrm{mg} \mathrm{m}^{-3}\right)$ & 1.861 & 1.897 & 2.084 \\
\hline No. of reflns for cell & 5370 & 5370 & 1083 \\
\hline $2 \theta \max (\mathrm{deg})$ & 29.985 & 34.257 & 26.297 \\
\hline$\mu / \mathrm{mm}^{-1}$ & 0.209 & 0.213 & 0.234 \\
\hline Reflns collected & 16407 & 24325 & 1505 \\
\hline Unique [Rint] & 2545 & 3500 & 310 \\
\hline No. $I>2 u(I)$ & 1636 & 2442 & 276 \\
\hline $\mathrm{T}_{\min } / \mathrm{T}_{\max }$ & $0.47 / 0.90$ & $0.43 / 0.90$ & $0.42 / 0.98$ \\
\hline Params & 161 & 161 & 80 \\
\hline$R_{1}[F>4 u(F)]$ & 0.037 & 0.0352 & 0.0773 \\
\hline $\mathrm{w} R_{2}\left(\mathrm{~F}^{2}\right.$, all data $)$ & 0.1166 & 0.088 & 0.1381 \\
\hline$S$ & 1.18 & 0.8515 & 1.0256 \\
\hline$\Delta \rho_{\max }, e \AA^{-3}$ & 0.24 & 0.35 & 0.25 \\
\hline$\Delta \rho_{\min }, e \AA^{-3}$ & -0.17 & -0.25 & -0.26 \\
\hline
\end{tabular}

Determinations of the cell parameters of the sample showed that a new phase of nitric acid had been grown at $1.6 \mathrm{GPa}$. The crystal was monoclinic, and its unit cell dimensions were $a=7.3163(4) \AA$, $b=8.4176(11) \AA, c=7.3135(11) \AA, \beta=116.895(6)^{\circ}$ and $V=$ 401.69(9) $\AA^{3}$ based on 1083 reflections $6<2 \theta<52^{\circ}$ with $Z^{\prime}=2$. The structure of the new phase was solved by direct methods, in space group $P 2_{1} / n$ ( $P 2_{1} / c$ in the conventional setting), using the program $S I R-92 .^{21}$

Structure refinements were carried out against $|F|$ using data with $I>3 \sigma(I){ }^{22}$ The hydrogen atoms were located in difference maps and all $\mathrm{OH}$ distances were refined with a more rigid distance restraint of $0.82(1) \AA$ owing to the lower completeness of the dataset. A twin component for a two-fold rotation around the $b$-direction was identified with ROTAX (as implemented in the CRYSTALS $S^{22}$ refinement package) and this yielded a twin scale factor of $61 \%$. All non-H atoms were modeled with anisotropic displacement parameters. Due to the low completeness of the data set $(39.8 \%)$ these were refined with similarity restraints.

Crystal structures were visualized using the programs $C A M E R O N^{28}$ and MERCURY. ${ }^{29,30}$ Analyses were carried out using PLATON ${ }^{31}$ as incorporated in the WIN-GX suite. ${ }^{32}$ Details of the crystal, data collection and refinement statistics are given in Table 1, while the refined bond lengths for each temperature (phase-I) and pressure (phase-II) are listed in Table 2.

\section{Confirmation of the high-pressure phase-II crystal structure of nitric acid-neutron powder-diffraction}

High-pressure neutron powder diffraction data were collected for $\mathrm{DNO}_{3}$ using the PEARL/HiPr diffractometer ${ }^{33,34}$ at the UK spallation neutron source, ISIS, located at the STFC Rutherford
Table 2 The refined intramolecular bond lengths for nitric acid using single crystal X-ray and neutron powder data

\begin{tabular}{|c|c|c|c|c|}
\hline & \multicolumn{4}{|c|}{ Bond lengths in Nitric acid/Å } \\
\hline & $210 \mathrm{~K}$ & $150 \mathrm{~K}$ & $1.6 \mathrm{GPa}$ & $1.55 \mathrm{GPa} /$ neutron \\
\hline N1-O11 & $1.193(2)$ & $1.2039(14)$ & $1.200(8)$ & $1.193(7)$ \\
\hline $\mathrm{N} 1-\mathrm{O} 21$ & $1.2518(16)$ & $1.2170(12)$ & $1.220(10)$ & $1.215(7)$ \\
\hline N1-O31 & $1.3213(17)$ & $1.3503(12)$ & $1.343(11)$ & $1.346(7)$ \\
\hline $\mathrm{O} 31-\mathrm{H} 31$ & $0.858(16)$ & $0.830(14)$ & $0.820(9)$ & $0.97(2)$ \\
\hline N2-O12 & $1.193(2)$ & $1.1945(14)$ & $1.198(9)$ & $1.203(7)$ \\
\hline $\mathrm{N} 2-\mathrm{O} 22$ & $1.2163(18)$ & $1.2229(13)$ & $1.233(10)$ & $1.223(7)$ \\
\hline N2-O32 & $1.3568(18)$ & $1.3596(13)$ & $1.330(9)$ & $1.351(7)$ \\
\hline O32-H32 & $0.851(16)$ & $0.875(14)$ & $0.820(9)$ & $0.88(2)$ \\
\hline N3-O13 & $1.189(2)$ & $1.2003(14)$ & & \\
\hline $\mathrm{N} 3-\mathrm{O} 23$ & $1.2205(16)$ & $1.2200(13)$ & & \\
\hline N3-O33 & $1.3541(17)$ & $1.3531(13)$ & & \\
\hline O33-H33 & $0.858(16)$ & $0.853(14)$ & & \\
\hline N4-O14 & $1.191(2)$ & $1.1987(13)$ & & \\
\hline $\mathrm{N} 4-\mathrm{O} 24$ & $1.2858(18)$ & $1.2835(13)$ & & \\
\hline N4-O34 & $1.287(2)$ & $1.2876(14)$ & & \\
\hline $\mathrm{O} 24-\mathrm{H} 24$ & $0.887(18)$ & $0.865(17)$ & & \\
\hline O34-H34 & $0.864(18)$ & $0.850(17)$ & & \\
\hline
\end{tabular}

Appleton Laboratory. The sample was added dropwise using a glass capillary into a TiZr capsule gasket ${ }^{35}$ filled with loosely packed silica wool which was used to inhibit the formation of large crystallites. A small pellet of aluminium foil was also included to act as a suitable pressure marker. The resulting capsule assembly was then compressed within a type V3b ParisEdinburgh $\left(P\right.$-E) pressure cell ${ }^{36,37}$ equipped with standard single toroid anvils with cemented WC cores (Ni binder). The P-E cell ram pressure was monitored and controlled by means of an automated hydraulic system. The experiment was conducted without the use of a pressure transmitting medium due to the chemically aggressive nature of the sample. As such, the maximum useful pressure was limited to $\sim 4 \mathrm{GPa}$ by the onset of diffraction peak broadening resulting from non-hydrostatic strains within the sample.

Time-of-flight (TOF) neutron powder diffraction data suitable for structure refinement were obtained by electronically focussing the 1080 individual detector element spectra of the main $2 \theta=$ $90^{\circ}$ detector bank. The summed pattern was then normalised with respect to the incident beam monitor and the scattering from a standard vanadium calibration sample. Lastly, the diffraction pattern intensities were corrected for the wavelength and scattering-angle dependence of the neutron attenuation by the P-E cell anvil (WC) and gasket (TiZr) materials. Sample pressures were calculated from the refined Al lattice parameters and the known room-temperature equation of state. ${ }^{38}$ Typical data collection times were $6 \mathrm{~h}$ at full ISIS beam, which equates to an integrated proton current of $\sim 1 \mathrm{~mA} \mathrm{~h}^{-1}$. Full-profile Rietveld refinements of the TOF neutron powder diffraction patterns were carried out using the GSAS/EXPGUI package (Fig. 1). ${ }^{39,40}$

Upon initial compression into phase-II we obtained a significantly textured powder pattern, as indicated by the azimuthal variation of the Bragg peak intensities about the incident beam direction. Data were collected with the sample in this textured state up to $3.8 \mathrm{GPa}$. The sample was carefully decompressed into the liquid phase, and then quickly recompressed into phase-II again at $1.4 \mathrm{GPa}$. By this means we obtained a powder pattern showing relatively little indication of texture which was suitable 
Table 3 Refined unit cell parameters of $\mathrm{DNO}_{3}$ phase II obtained from neutron diffraction measurements

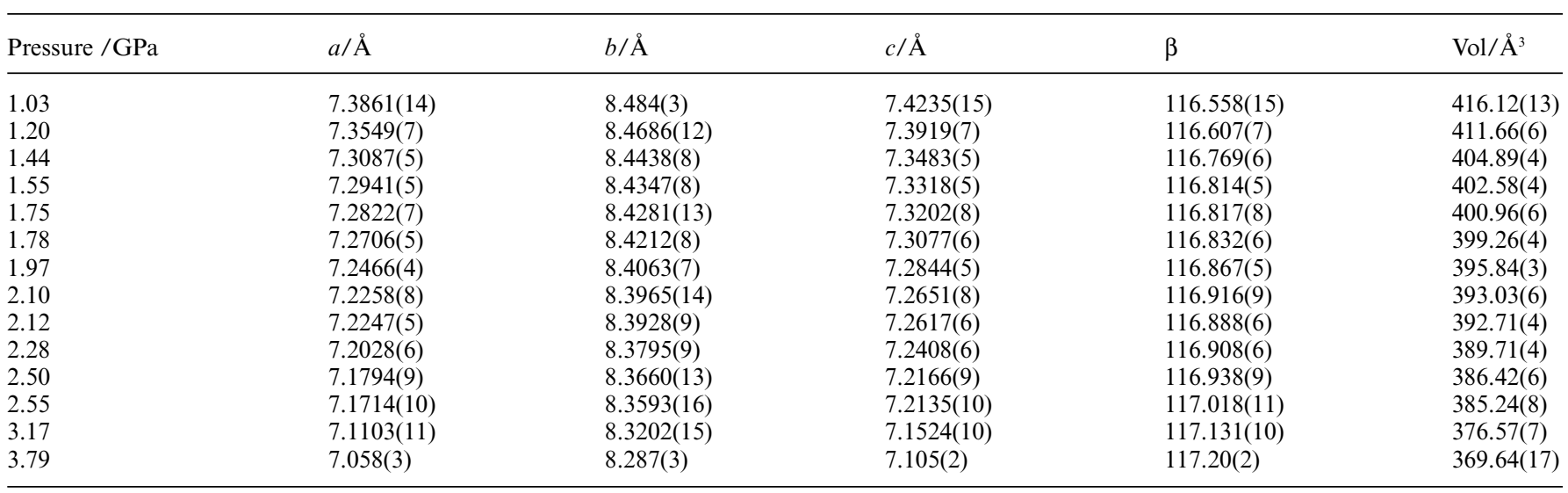

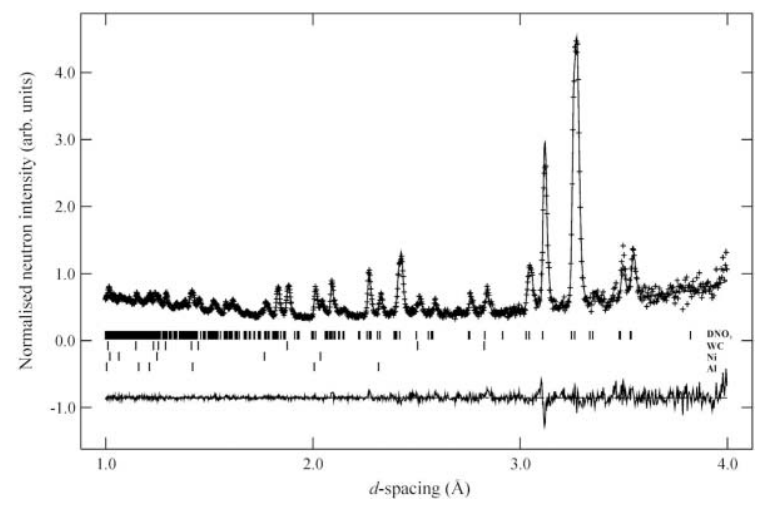

Fig. 1 Neutron powder pattern of phase II of perdeuterated nitric acid at 1.55(2) GPa at RT. The difference curve is shown below.

for the purpose of structure refinement. The refined unit cell parameters for the compression of $\mathrm{DNO}_{3}$ nitric acid can be found in Table 3. Fig. 2 shows the room-temperature equation-of-state of $\mathrm{DNO}_{3}$ phase-II over the useful 1-4 GPa interval of the present study.

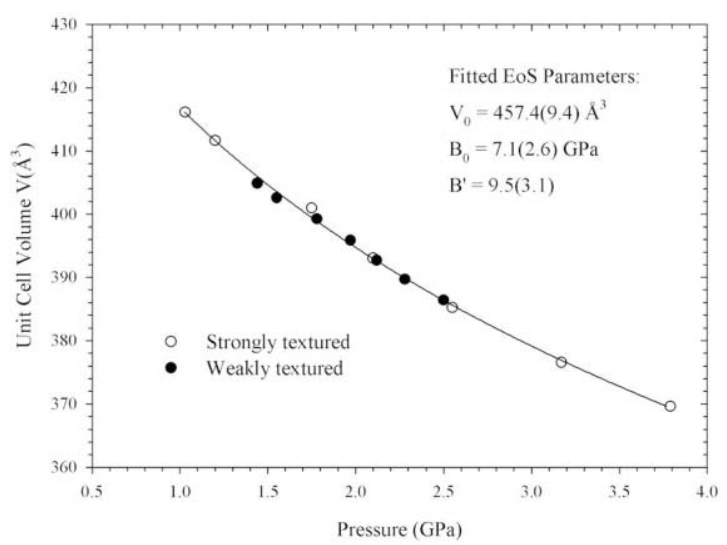

Fig. 2 Variation of the unit cell volume of $\mathrm{DNO}_{3}$ as a function of pressure. The open and closed circles represent data collected from strongly and weakly textured patterns, respectively.

\section{Results and discussion}

\section{The ambient-pressure phase-I crystal structure of nitric acid}

The crystal structure of nitric acid was first published by Luzzati ${ }^{13}$ and found to crystallise in space group $P 2_{1} / c$ with four molecules in the asymmetric unit (Fig. 3). The present re-determination was carried out to provide a more complete and precise structural model for comparison with the new high-pressure structure.

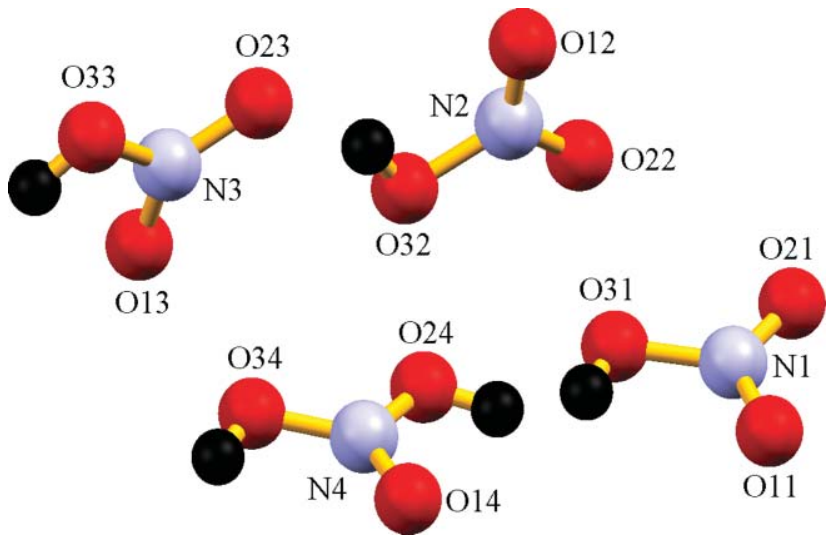

Fig. 3 Asymmetric unit of nitric acid phase I with atom labelling scheme.

Three of the molecules are ordered with the hydrogen atom bonded to $\mathrm{O} 3 x$ (where $x$ is the molecule number). The fourth molecule (labelled molecule 4) lies in the proximity of an inversion centre that forces the hydrogen atom to be disordered; this observation was made by Luzzati in his earlier study. In both studies, the presence of a disordered hydrogen atom is implied by the $\mathrm{N}-\mathrm{O}$ bond lengths present in the molecule. Luzzati found that all the $\mathrm{N}-\mathrm{O}$ bond lengths present in the disordered molecule were approximately equal whereas the three other molecules exhibited one longer bond that could be assigned to the single $\mathrm{N}-\mathrm{O}$ bond. The increased precision afforded by our re-determination has allowed us to observe that in the case of molecule 4 there is one bondlength that is typical of an $\mathrm{N}-\mathrm{O}$ double bond $(\sim 1.20 \AA)$ and two equal $\mathrm{N}-\mathrm{O}$ bondlengths intermediate in value $(\sim 1.28 \AA)$ between that of an $\mathrm{N}-\mathrm{O}$ single and double bond (Table 2). 
The phase-I structure is composed of catemeric hydrogenbonded chains running along the $b$-direction (Fig. 4). Of the four molecules present in the structure two molecules (labelled 1 and 4) form hydrogen bonds to symmetry-related neighbours, whereas the remaining two molecules $(2 \& 3)$ hydrogen bond together to form the third catemeric chain. Molecule 1 sits on a 2 -screw axis enabling the formation of a hydrogen bond to a symmetry equivalent molecule $\left(\mathrm{O} 31 \cdots \mathrm{O} 21^{\prime} 2.7410(13) \AA\right.$, at $150 \mathrm{~K})$. As discussed above, molecule 4 resides in close proximity to an inversion centre and hence the catemeric chain is formed by hydrogen bonds to itself $\left(\mathrm{O} 24 \cdots \mathrm{O} 24^{\prime} 2.7572(14) \AA\right.$ А; O34 … O34' $2.7390(15) \AA$, at $150 \mathrm{~K}$ ). The third chain is formed by hydrogen bonds between molecules 2 and 3 mimicking a $2{ }_{1}$-screw axis $\left(\mathrm{O} 32 \cdots \mathrm{O} 23^{\prime} 2.7400(14) \AA ̊\right.$; O33 ‥ O22' 2.7543(14) $\AA$, at $\left.150 \mathrm{~K}\right)$.

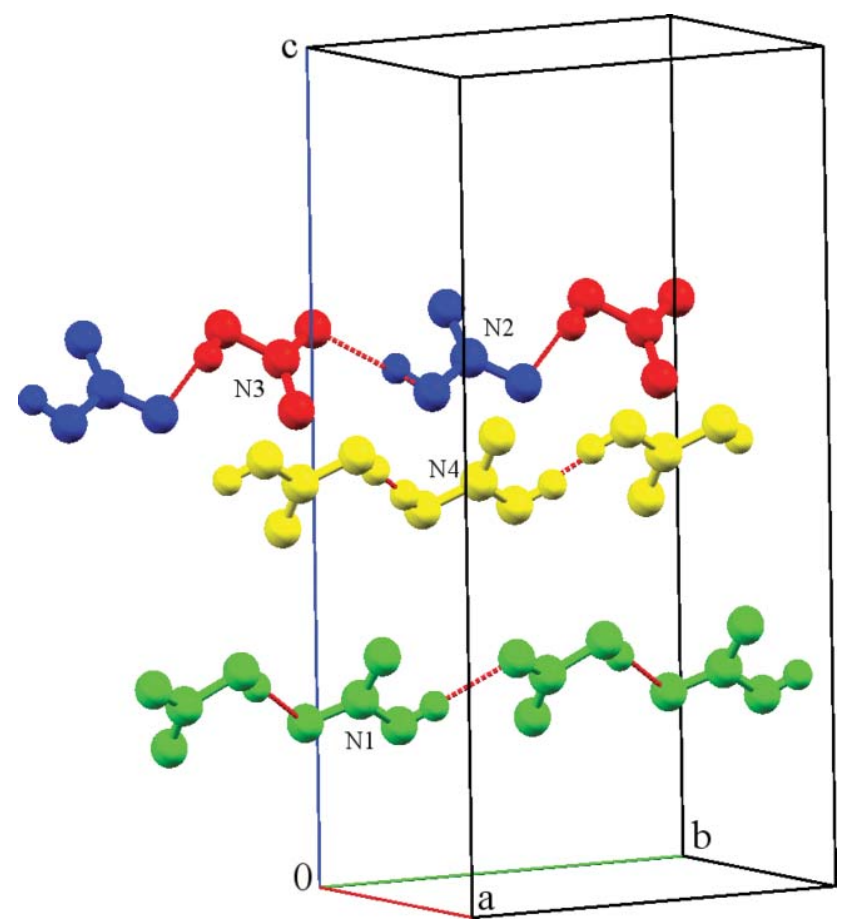

Fig. 4 Catemeric chains of nitric acid phase I. The molecules are coloured by symmetry equivalence.

The structure is layered parallel to the $\left(\begin{array}{lll}1 & 0 & 0\end{array}\right)$ planes with a herring-bone motif formed by the molecules in different layers when the structure is viewed down the $b$-direction (Fig. 5). The chains that are composed of molecules 2 and 3 are situated at $a=$ 0,1 etc. The other two chains are sandwiched between these layers at $a=\frac{1}{2}$. There are interactions between the layers in the form of typical van der Waals contacts between oxygen and nitrogen atoms. The interactions involving the ordered molecules all have similar $\mathrm{O} \cdots \mathrm{N}$ contact distances ranging from $2.9462(15) \AA$ to $2.9527(15) \AA$ at $150 \mathrm{~K}$. In the case of the disordered molecule, the change in charge density on the nitrogen atom results in a significantly shorter contact between $\mathrm{O} 32$ and $\mathrm{N} 4(\mathrm{O} 32 \cdots \mathrm{N} 4$ $2.9120(15) \AA$, at $150 \mathrm{~K})$.

\section{The high-pressure phase-II crystal structure of nitric acid}

The high-pressure phase-II crystal structure of nitric acid has a number of similarities with the low-temperature phase-I structure:

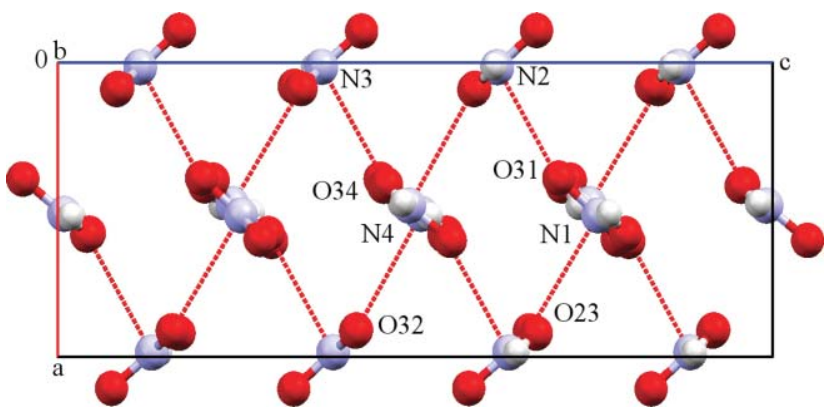

Fig. 5 The $\mathrm{HNO}_{3}$ phase I structure viewed down the b-axis showing the interchain close contacts between nitrogen and oxygen atoms.

both crystallise in $P 2_{1} / c$ crystal symmetry (with phase-II refined in the $P 2_{1} / n$ setting) and both structures are characterized by the formation of hydrogen-bonded molecular catemers (Fig. 6). The catemers are directed along the monoclinic $b$-axis, which has a similar repeat distance of 8.6046(4) $\AA$ for phase-I (at $210 \mathrm{~K}$ ) and $8.4176(11) \AA$ for phase-II (at $293 \mathrm{~K}$ ). The catemers also pack in a herringbone arrangement for both phases and it is interesting to note that the unit cells are related to one another through the transformation, $\left(-\frac{1}{2} 0 \frac{1}{2}, 0-10,202\right)$. This transforms the phase-II cell, $a=6.2335(5) \AA, b=8.4176(11) \AA, c=15.3110(18) \AA, \beta=$ $90.025(10)^{\circ}, V=803.38(18) \AA^{3}$, to a cell comparable to that of phase-I $(a=6.3689(3) \AA, b=8.6046(4) \AA, c=16.4141(9) \AA$, $\left.\beta=90.055(4) \AA, V=899.52(8) \AA^{3}\right)$ with a $10.7 \%$ reduction in volume at $1.6 \mathrm{GPa}$. Both molecules in the asymmetric unit of phase-II are placed on 2 -screw axes, so enabling them to form hydrogen bonds to symmetry equivalent molecules giving

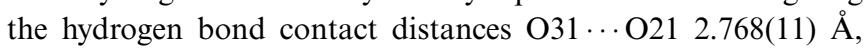
$\mathrm{O} 32 \ldots \mathrm{O} 22$ 2.693(11) $\AA$. The catemers are arranged with a similar herring-bome motif to that observed in the low-temperature phase but in phase II the layers are set parallel to the $(10-1)$ planes. The van der Waals contacts between oxygen and nitrogen atoms on different layers range from 2.891(10) ̊ to 3.240(13) $\AA$.

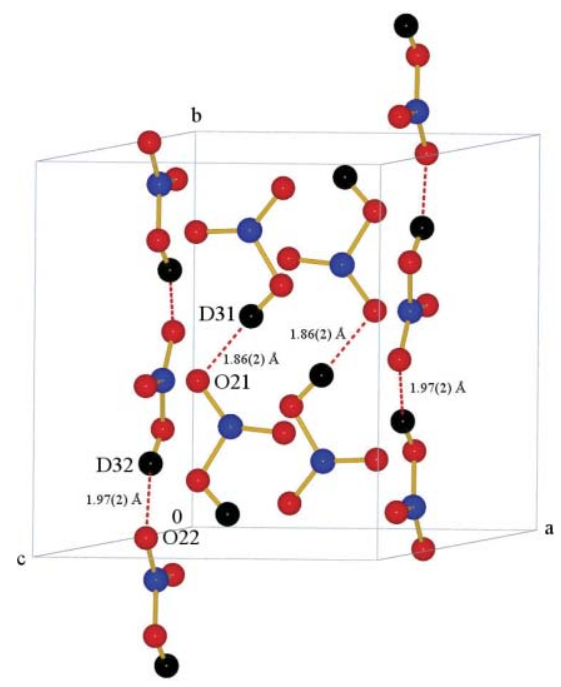

Fig. 6 Catemeric chains formed in the high-pressure phase II.

The results of the high-pressure neutron powder diffraction study are broadly similar to those obtained by single-crystal $\mathrm{X}$-ray diffraction methods, although the difference between the 
$\mathrm{O} 31(-\mathrm{D} 31) \cdots \mathrm{O} 21$ and the $\mathrm{O} 32(-\mathrm{D} 32) \cdots \mathrm{O} 22$ bond lengths is much reduced: here the hydrogen bonding distances are 2.83(3) $\AA$ and 2.83(2) $\AA$, respectively, at $1.55 \mathrm{GPa}$ with corresponding O$\mathrm{D} \cdots \mathrm{O}$ bond angles of $175(2)^{\circ}$ and $165(3)^{\circ}$. The phase-II hydrogen bond contact distances obtained from the neutron diffraction study are slightly longer than those determined by single-crystal X-ray diffraction methods, despite the pressures for both studies being broadly similar. In the absence of any other obvious cause for this systematic offset, we suggest this to be a consequence of deuteration.

\section{Comparing intermolecular interactions: Hirshfeld surfaces and fingerprint plots}

The comparison of Hirshfeld surfaces and fingerprint plots, produced with CRYSTAL EXPLORER, ${ }^{41,42}$ can be a powerful tool for the identification of key differences in the intermolecular contacts and interactions of the various polymorphs of a particular molecular species. It is the uniqueness of the Hirshfeld surfaces for any crystal structure that makes them a powerful tool for comparing the intermolecular contacts of the same molecule in different crystal environments, such as those of different polymorphs, as well as for the identification of common trends or features in identifiable classes of compound. Additionally, the fingerprint plots generated from the surfaces provide a concise and useful summary of the various interactions in a crystal structure by mapping the fraction of points on the corresponding Hirshfeld surface as a function of the closest distance to nuclei interior $\left(d_{i}\right)$ and exterior $\left(d_{e}\right)$ to the surface.

The corresponding $d_{\text {norm }}$ surfaces for the low-temperature $(150 \mathrm{~K})$ and high-pressure phases (X-ray data) are shown in Fig. 7 (upper) and (lower) respectively, while the corresponding fingerprint plots are shown in Fig. 8 (upper) and (lower). Note that to avoid physically unreasonable $\mathrm{H}-\mathrm{H}$ contacts for the disordered molecule (containing N4) in phase I, a structural model was produced for the calculation of the Hirshfeld surfaces where the symmetry was reduced from $P 2_{1} / c$ to $P 2_{1}$, thereby removing the inversion centre. The additional molecules required to complete the structure were generated by applying the $c$-glide symmetry operation and the disordering was removed by fixing hydrogen atoms H24 and H34 into ordered positions with the "sense" of the hydrogen bond directed along $[0-10]$.

The resulting $d_{\text {norm }}$ surfaces for the four molecules in the asymmetric unit of phase I are broadly similar and each shows the same colour contour features indicative of the relatively strong and short hydrogen bond contacts. The $d_{\text {norm }}$ surfaces for the molecules in the high-pressure phase II, shown in Fig. 7 (lower), are generally very similar to those of phase I. However, it is clear from the greater prominence of yellow areas on the phase II surfaces that the $\mathrm{HNO}_{3}$ molecules of high-pressure phase are subject to significantly stronger intermolecular interactions from contacts not involving the hydrogen bonds. Note that the colours in these surfaces were determined with CrystalExplorer 2.0 with the extra highlights feature toggled. This suppresses the green hues which are characteristic of conventional Hirshfeld plots. This is also reflected in the fingerprint plots (Fig. 8) where the red areas, indicating a large number of non-bonding $\mathrm{O} \cdots \mathrm{O}$ intermolecular contacts, are at shorter $d_{e}$ and $d_{i}$ distances for the high-pressure structure: i.e. the centre of mass of the fingerprint plots are moved
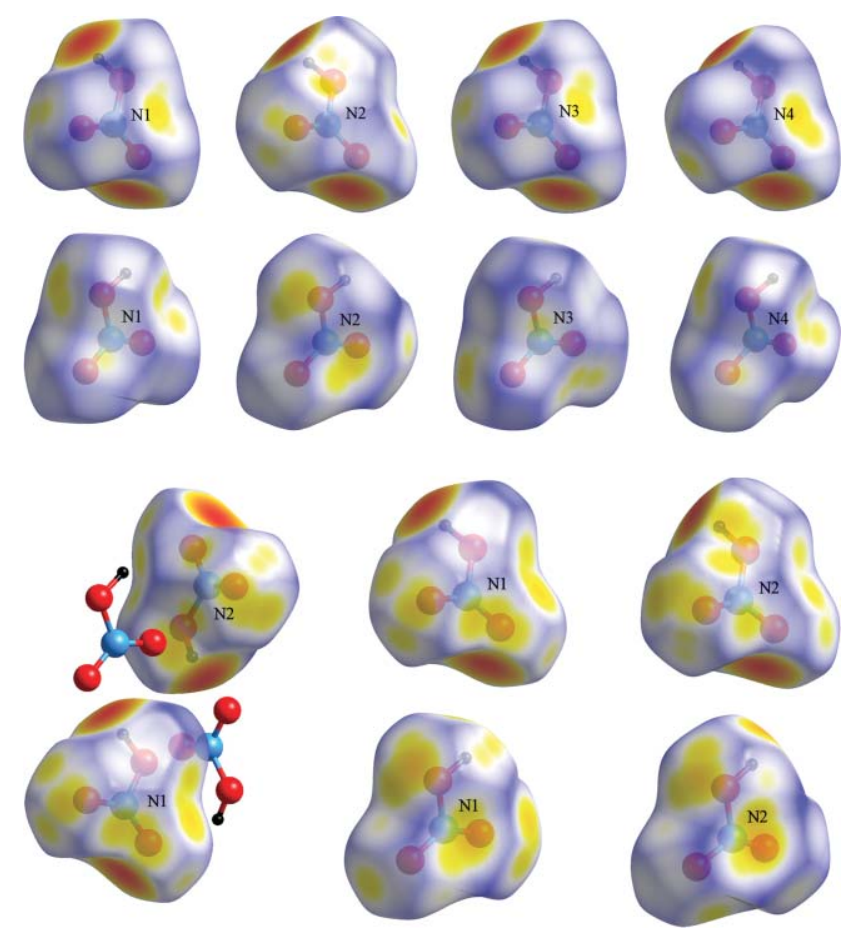

Fig. 7 Hirshfeld surfaces $\left(d_{\text {norm }}\right)$ for nitric acid phase I (upper row) and phase II (lower row). For phase I, two views are shown for each molecule in the asymmetric unit. Note that the disordered molecule containing N4 is shown with the hydrogen in one of its two possible locations. For phase II, the arrangement of molecules in neighbouring chains is shown on the left while two views of each molecule in the asymmetric unit are also shown. The figures were prepared using the CrystalExplorer v2.0 with the extra highlight option toggled.

to shorter distances (towards the origin) with pressure. Although this is to be expected, it is perhaps more significant that the "spikes" on the fingerprint plots, associated with the $\mathrm{O}-\mathrm{H} \cdots \mathrm{O}$ hydrogen bonds, are barely changed with pressure. The apparent incompressibility of the hydrogen bonds in nitric acid compared to the hydrogen bonding interactions in other systems (see for example G.A. Jeffries ${ }^{43}$ ) is entirely consistent with their relative strength.

In their high-pressure Raman spectroscopy study, Lucas and Petitet $^{14}$ assumed that the low-temperature phase-I structure is formed on initial compression of the liquid. In the current study, however, we have observed that this is not the case and instead a previously unobserved high-pressure phase, here termed phase-II, is found to be present under these conditions. Although some of the details of the Lucas and Petitet's study will require some reinterpretation, because the low-temperature phase I structure and the high-pressure phase II structure share a common hydrogen-bonded catameric arrangement of the molecules with a similar herring-bone packing arrangement, their general conclusions about the overall response of the hydrogen bonds and intermolecular contacts to pressure remain fully justified. The structural behaviour of nitric acid above $10 \mathrm{GPa}$ is beyond the scope of the current study and the putative ionization of the molecules in this pressure range will require alternative highpressure techniques. However, the current study does provide a more accurate starting model for follow-up calculations to those conducted by Méreau and Mathieu, ${ }^{15}$ which lacked reliable 

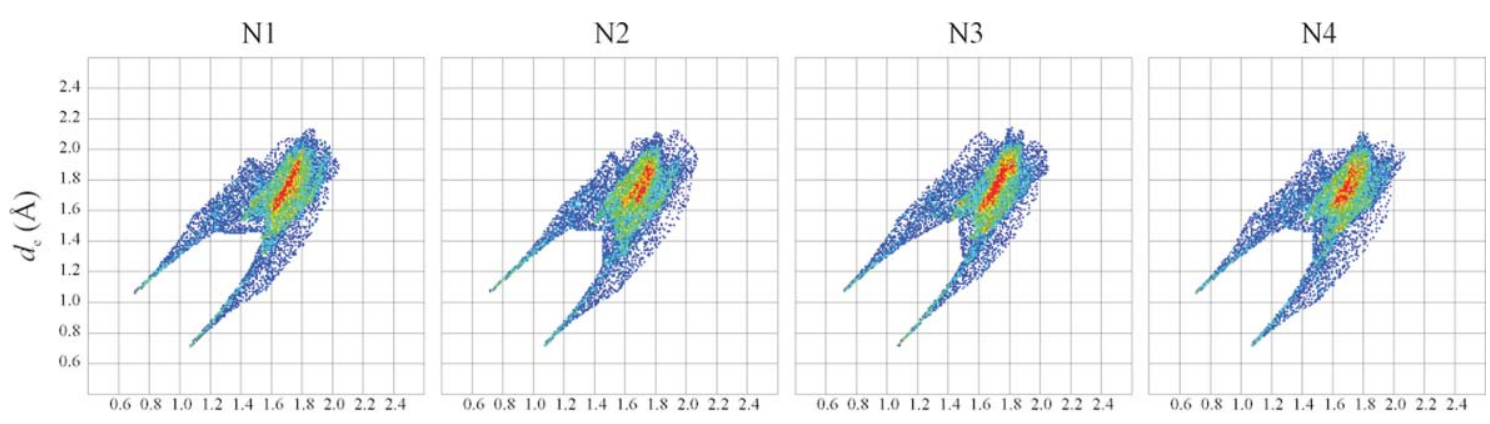

$d_{i}(\AA)$

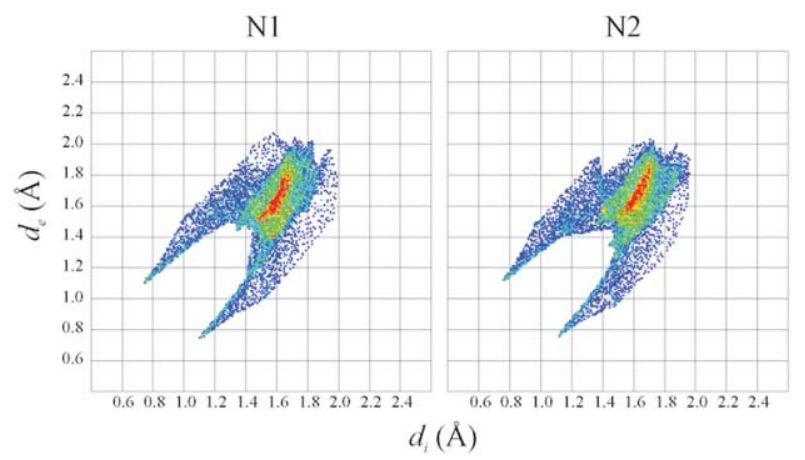

Fig. 8 Fingerprint plots for nitric acid phase I (upper row) and phase II (lower row).

hydrogen atom positions and, hence, contained some assumptions about the hydrogen atom positions which were subsequently used in the structural model for the high-pressure calculations.

\section{Conclusions}

We have solved the high-pressure-crystal structure of nitric acid using a combination of single-crystal X-ray diffraction and neutron powder diffraction techniques. The crystal structure of the low-temperature phase of nitric acid has also been redetermined. The crystal structures are strikingly similar, in that they are both composed of hydrogen-bonded molecular catemers arranged in a herring-bone packing motif, and there is a relatively simple geometric transformation between them. The key difference between the phases appears to be the molecular disorder in one of the catemers within the low-temperature structure, which increases the number of symmetry inequivalent catemers from 2 to 3 with a concomitant increase in the unit cell volume. Detailed examination of the intermolecular contacts and bonding reveals that much of the compression on pressure increase is accommodated by the relatively weak inter-catemer interactions while the hydrogen bond contact distances remain relatively unaltered. This appears to be consistent with the strength of the $\mathrm{O}-\mathrm{H} \cdots \mathrm{O}$ hydrogen bond in nitric acid.

\section{Acknowledgements}

The authors would like to thank the ISIS Facility of the STFC Rutherford Appleton Laboratory for the allocation of neutron beamtime, the Leverhulme Trust for funding (IDHO) and the Engineering and Physical Sciences Research Council (EPSRC) for additional funding.

\section{Notes and references}

1 H. Grothe, H. Tizek and I. K. Ortega, Faraday Discuss., 2008, 137, 223-234.

2 C. Voigt, J. Schreiner, A. Kohlmann, P. Zink, K. Mauersberger, N. Larsen, T. Deshler, C. Kroger, J. Rosen, A. Adriani, F. Cairo, G. Di Donfrancesco, M. Viterbini, J. Ovarlez, H. Ovarlez, C. David and A. Dornbrack, Science, 2000, 290, 1756-1758.

3 D. W. Fahey, R. S. Gao, K. S. Carslaw, J. Kettleborough, P. J. Popp, M. J. Northway, J. C. Holecek, S. C. Ciciora, R. J. McLaughlin, T. L. Thompson, R. H. Winkler, D. G. Baumgardner, B. Gandrud, P. O. Wennberg, S. Dhaniyala, K. McKinney, T. Peter, R. J. Salawitch, T. P. Bui, J. W. Elkins, C. R. Webster, E. L. Atlas, H. Jost, J. C. Wilson, R. L. Herman, A. Kleinbohl and M. von Konig, Science, 2001, 291, 1026-1031.

4 H. Tizek, E. Knozinger and H. Grothe, Phys. Chem. Chem. Phys., 2002, 4, 5128-5134.

5 H. Grothe, H. Tizek, D. Waller and D. J. Stokes, Phys. Chem. Chem. Phys., 2006, 8, 2232-2239.

6 N. Lebrun, F. Mahe, J. Lamiot, M. Foulon, J. C. Petit and D. Prevost, Acta Crystallogr., Sect. B: Struct. Sci., 2001, 57, 27-35.

7 N. Lebrun, F. Mahe, J. Lamiot, M. Foulon and J. C. Petit, Acta Crystallogr., Sect. C: Cryst. Struct. Commun., 2001, 57, 11291131.

8 M. Walker, C. A. Morrison and D. R. Allan, Phys. Rev. B: Condens. Matter Mater. Phys., 2005, 72, 224106.

9 M. Walker, C. R. Pulham, C. A. Morrison, D. R. Allan and W. G. Marshall, Phys. Rev. B: Condens. Matter Mater. Phys., 2006, 73, 224110.

10 D. R. Allan, S. J. Clark, A. Dawson, P. A. McGregor and S. Parsons, J. Chem. Soc., Dalton Trans., 2002, 1867-1871.

11 F. P. A. Fabbiani, D. R. Allan, A. Dawson, D. J. Francis, W. G. Marshall and C. R. Pulham, Inorg. Chim. Acta, 2008, 361, 487494.

12 D. R. Allan, C. A. Morrison, S. Z. Ismail, C. R. Pulham, F. P. A. Fabbiani and W. G. Marshall, in preparation.

13 V. Luzzati, Acta Crystallogr., 1951, 4, 120-131.

14 H. Lucas and J. P. Petitet, J. Phys. Chem. A, 1999, 103, 89528958.

15 R. Mereau, D. Mathieu, M. Elstner and T. Frauenheim, Phys. Rev. B: Condens. Matter Mater. Phys., 2004, 69, 104101. 
16 R. Boese \& M. Nussbaumer, (1994). In Correlations, Transformations, and Interactions in Organic Crystal Chemistry, D. W. Jones, A Katrusiak, ed.; Crystallographic Symposia 7, International Union of Crystallography, Chester, U.K 20-37.

17 Bruker-Nonius, SMART version 5.624 Bruker-AXS, Madison, WI, 2001.

18 J. Cosier and A. M. Glazer, J. Appl. Crystallogr., 1986, 19, 105107.

19 G. M. Sheldrick, SADABS Version 2004-1. Bruker-AXS, Madison, WI, 2004.

20 R. H. Blessing, Acta Crystallogr., Sect. A: Found. Crystallogr., 1995, 51, 33-38.

21 A. Altomare, G. Cascarano, C. Giacovazzo and A. Guagliardi, J. Appl. Crystallogr., 1994, 27, 1045-1050.

22 P. W. Betteridge, J. R. Carruthers, R. I. Cooper, K. Prout and D. J. Watkin, J. Appl. Crystallogr., 2003, 36, 1487.

23 L. Merrill and W. A. Bassett, Rev. Sci. Instrum., 1974, 45, 290 294.

24 G. J. Piermarini, S. Block, J. D. Barnett and R. A. Forman, J. Appl. Phys., 1975, 46, 2774-2780.

25 A. Dawson, D. R. Allan, S. Parsons and M. Ruf, J. Appl. Crystallogr., 2004, 37, 410-416and references therein.

26 Bruker-Nonius, SAINT version 7. Bruker-AXS, Madison, WI, 2003.

27 S. Parsons, SHADE, University of Edinburgh, 2004.

28 D. J. Watkin, L. Pearce and C. K. Prout, CAMERON-A Molecular Graphics Package. Chemical Crystallography Laboratory, University of Oxford, England, 1993.

29 R. Taylor and C. F. Macrae, Acta Crystallogr., Sect. B: Struct. Sci, 2001, 57, 815-827.
30 I. J. Bruno, J. C. Cole, P. R. Edgington, M. Kessler, C. F. Macrae, P. McCabe, J. Pearson and R. Taylor, Acta Crystallogr., Sect. B: Struct. Sci., 2002, 58, 389-397.

31 A. L. Spek, J. Appl. Crystallogr., 2003, 36, 7-13.

32 L. J. Farrugia, J. Appl. Crystallogr., 1999, 32, 837-838.

33 ISIS, Dedicated Facility for High Pressure Diffraction, in ISIS 96ISIS Facility Annual Report 1995-96, (1996), RutherfordAppleton Laboratory, 1996, vol. RAL-TR-96-050, 61-62.

34 ISIS, PEARL - Pressure and Engineering Research Line. ISIS 97 ISIS Facility Annual Report 1996-97, (1997), Rutherford Appleton Laboratory, Vol. RAL-TR-97-050, 28-29.

35 W. G. Marshall and D. J. Francis, J. Appl. Crystallogr., 2002, 35, 122125.

36 R. J. Nelmes, J. S. Loveday, R. M. Wilson, J. M. Besson, S. Klotz, G. Hamel, S. Hull, (1994). Proceedings of the Symposium on Time-of-Flight Diffraction at Pulsed Neutron Sources, J. D. Jorgensen, A. J. Schultz, ed. Amer Crystallographic Assoc: Buffalo, 29, 19-27.

37 J. M. Besson, R. J. Nelmes, G. Hamel, J. S. Loveday, G. Weill and S. Hull, Phys. B, 1992, 180, 907-910.

38 R. G. Greene, H. Luo and A. L. Ruoff, Phys. Rev. Lett., 1994, 73, 2075-2078.

39 A. C. Larson, and R. B. Von Dreele, 2004, "General Structure Analysis System (GSAS)", Los Alamos National Laboratory Report LAUR 86-748.

40 B. H. Toby, J. Appl. Crystallogr., 2001, 34, 210-213.

41 M. A. Spackman and J. J. McKinnon, CrystEng Comm, 2002, 4, 378392.

42 J. J. McKinnon, M. A. Spackman and A. S. Mitchell, Acta Crystallogr., Sect. B: Struct. Sci., 2004, 60, 627-668.

43 G. A. Jeffries, 1997, Oxford University Press, New York. 